\title{
Literature Review for Oxalate Oxidation Processes and Plutonium Oxalate Solubility
}

C. A. Nash

January, 2012

Savannah River National Laboratory Savannah River Nuclear Solutions, LLC Aiken, SC 29808

Prepared for the U.S. Department of Energy under contract number DE-AC09-08SR22470.

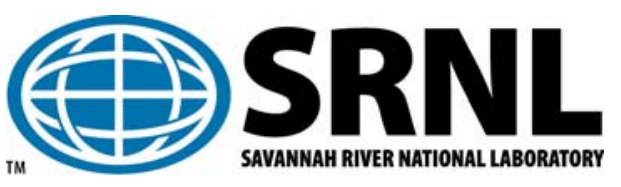


SRNL-STI-2012-00003

Revision 0

\section{DISCLAIMER}

This work was prepared under an agreement with and funded by the U.S. Government. Neither the U.S. Government or its employees, nor any of its contractors, subcontractors or their employees, makes any express or implied:

1. warranty or assumes any legal liability for the accuracy, completeness, or for the use or results of such use of any information, product, or process disclosed; or

2. representation that such use or results of such use would not infringe privately owned rights; or

3. endorsement or recommendation of any specifically identified commercial product, process, or service.

Any views and opinions of authors expressed in this work do not necessarily state or reflect those of the United States Government, or its contractors, or subcontractors.

\section{Printed in the United States of America \\ Prepared for \\ U.S. Department of Energy}




\section{REVIEWS AND APPROVALS}

\section{AUTHORS:}

C. A. Nash, Advanced Characterization and Processing Group

Date

TECHNICAL REVIEW:

M. C. Thompson, Separations \& Actinide Science Programs

Date

T. C. Shehee, Separations \& Actinide Science Programs

Date

APPROVAL:

S. D. Fink, Manager

Date

Separations \& Actinide Science Programs

S.L. Marra, Manager

Date

Environmental \& Chemical Process Technology Research Programs

W. G. Dyer, Manager

Date

Outside Facilities and Technical Support Engineering 
SRNL-STI-2012-00003

Revision 0

\section{ACKNOWLEDGEMENTS}

The efforts of Jack Zamecnik in performing scoping calculations for solution chemistry cases with OLI Software is acknowledged. 


\section{EXECUTIVE SUMMARY}

A literature review of oxalate oxidation processes finds that manganese(II)-catalyzed nitric acid oxidation of oxalate in precipitate filtrate is a viable and well-documented process. The process has been operated on the large scale at Savannah River in the past, including oxidation of 20 tons of oxalic acid in F-Canyon. Research data under a variety of conditions show the process to be robust. This process is recommended for oxalate destruction in H-Canyon in the upcoming program to produce feed for the MOX facility.

Prevention of plutonium oxalate precipitation in filtrate can be achieved by concentrated nitric acid/ferric nitrate sequestration of oxalate. Organic complexants do not appear practical to sequester plutonium.

Testing is proposed to confirm the literature and calculation findings of this review at projected operating conditions for the upcoming campaign. 


\section{TABLE OF CONTENTS}

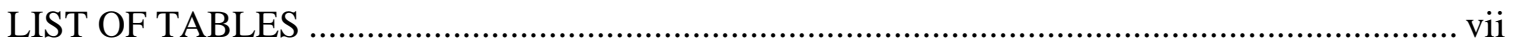

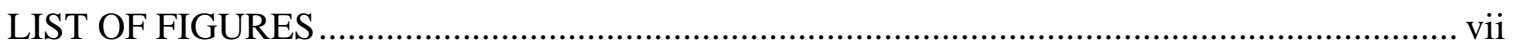

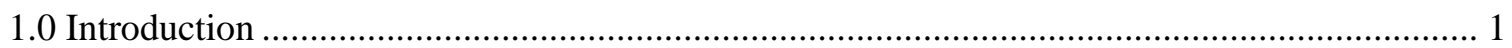

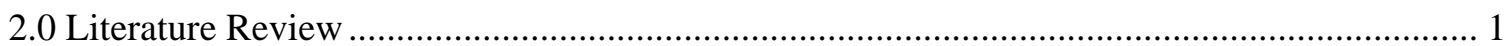

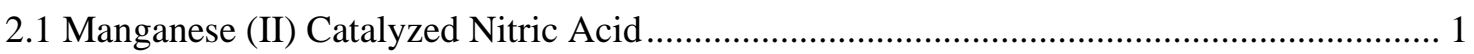

2.1.1 Large Scale Applications of the Manganese(II)/Nitric Process ...................................... 2

2.1.2 Kinetics Information for the Manganese(II)/Nitric Reaction......................................... 3

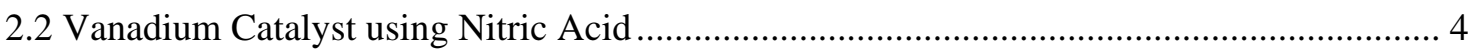

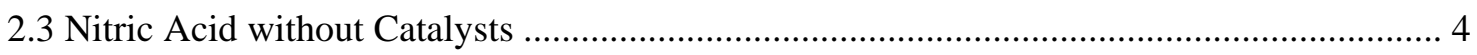

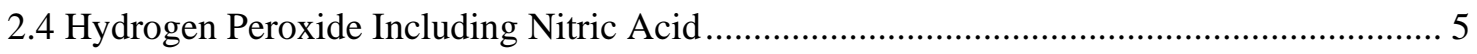

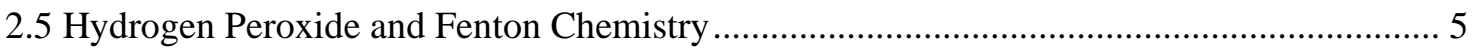

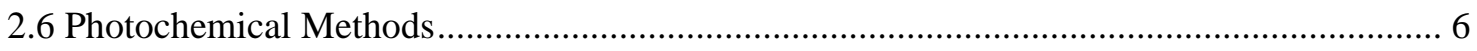

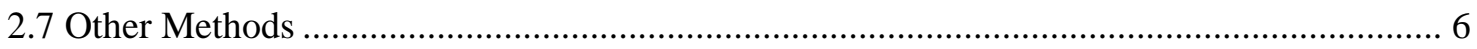

3.0 Post Filtration Precipitation of Plutonium Oxalate............................................................... 6

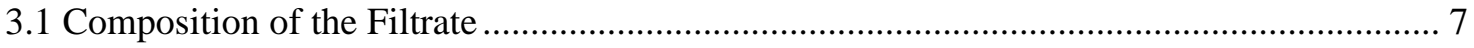

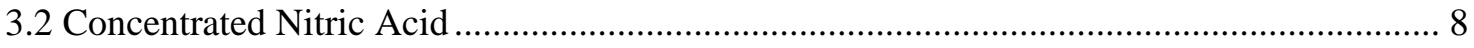

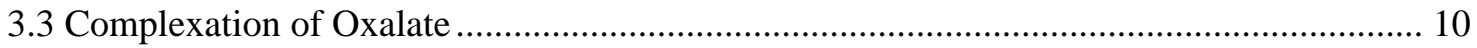

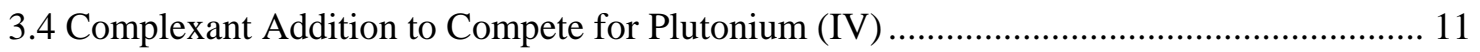

3.5 Solubility of Gadolinium Oxalate in Nitric Acid............................................................... 12

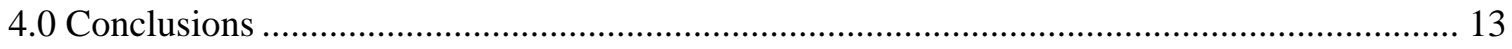

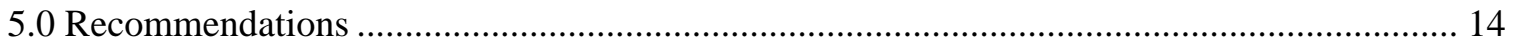

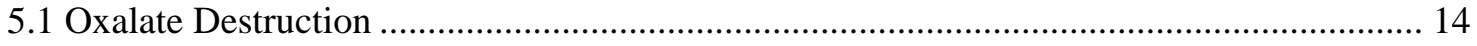

5.2 Example Calculation for Rate of Oxalate Destruction........................................................ 14

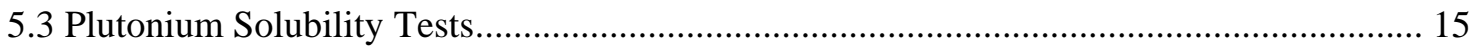

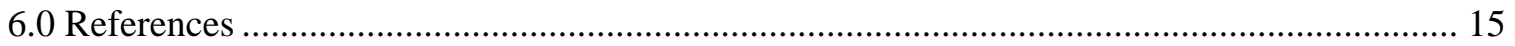




\section{LIST OF TABLES}

Table 1. Filtrate Composition Ranges ………........................................................................... 7

Table 2. Plutonium Concentration from Oxalate Filtration ${ }^{\text {xxvi }}$................................................... 8

Table 3. Plutonium Solubility as Oxalate, mg/L, predicted by Reas Work.................................. 10

Table 4. Plutonium Solubility as Oxalate, mg/L, predicted by Gel'man .................................... 10

Table 5. Percent Oxalate Sequestered Under Varied Conditions ................................................ 11

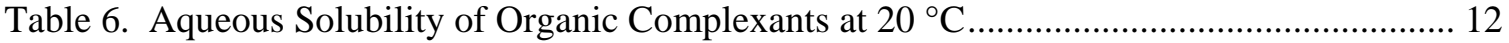

Table 7. Solubility of Gadolinium Oxalate in Nitric Acid ${ }^{\mathrm{xxxviii}}$................................................... 13

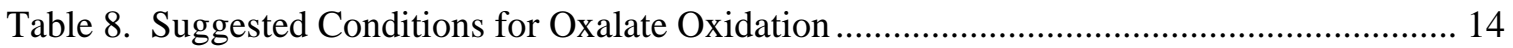

Table 9. Calculated Time Needed for 99.9\% Oxalate Destruction ............................................ 15

\section{LIST OF FIGURES}

Figure 1. Time to Oxidize 95\% Oxalate vs. Rate Constant.......................................................... 3

Figure 2. Effect of Temperature on Reaction Rate....................................................................... 4

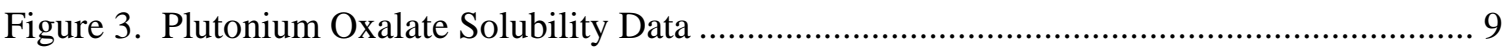




\section{LIST OF ABBREVIATIONS}

$\begin{array}{ll}\text { EDTA } & \text { Ethylenediaminetetraacetic acid } \\ \text { Fp } & \text { [Total oxalate concentration]/[square of hydrogen ion concentration] } \\ \text { mM } & \text { Millimolar } \\ \text { MOX } & \text { Mixed Oxide Fuel } \\ \text { SRNL } & \text { Savannah River National Laboratory } \\ \text { TTR } & \text { Technical Task Request } \\ \text { UV } & \text { Ultraviolet (light) }\end{array}$




\subsection{Introduction}

$\mathrm{H}$ Canyon plans to commence conversion of plutonium metal to low-fired plutonium oxide in 2012 for eventual use in the Mixed Oxide Fuel (MOX) Facility. The flowsheet includes sequential operations of metal dissolution, ion exchange, elution, oxalate precipitation, filtration, and calcination. All processes beyond dissolution will occur in HB-Line. The filtration step produces an aqueous filtrate that may have as much as $4 \mathrm{M}$ nitric acid and $0.15 \mathrm{M}$ oxalate. The oxalate needs to be removed from the stream to prevent possible downstream precipitation of residual plutonium when the solution is processed in $\mathrm{H}$ Canyon. In addition, sending the oxalate to the waste tank farm is undesirable. This report addresses the processing options for destroying the oxalate in existing $\mathrm{H}$ Canyon equipment.

This literature search builds on previous reviews and literature because oxidation of oxalate is needed in many other processes. One example is the treatment of oxalic acid solutions used for nuclear waste tank cleanout. Another example has been previous "oxalate kill” work for the processing of actinides. Some industrial processes also need oxalate removal in chemical wastewater treatment.

This literature search also addresses the issue of post-filtration solids (plutonium oxalate). Filtration of the plutonium oxalate slurry will carry some plutonium through the filter because of a small soluble fraction of plutonium oxalate as well as submicron fines that may pass through the filter. Chemical means of removing and preventing post filtration solids are reviewed.

This report is a deliverable per Technical Task Request (TTR) NMMD-HTS-2011-3175. ${ }^{\text {. }}$

\subsection{Literature Review}

The sections below are organized by type of process studied to destroy oxalate that is in aqueous solution.

\subsection{Manganese (II) Catalyzed Nitric Acid}

A history of success of this process is indicated by Bibler et al. in a Technical Data Summary. ${ }^{\text {ii }}$ A solution containing oxalic and nitric acid has manganese (II), typically manganous nitrate, added. Heating of the solution to near $100{ }^{\circ} \mathrm{C}$ will consume the oxalic acid at the expense of nitric acid with a practical reaction rate. Carbon dioxide will be evolved along with nitrogen oxides, typically nitric oxide (NO). Bibler's report was directed at the oxidation of oxalic acid tank cleaning solutions, and tank sludge including iron and aluminum was often present. Added manganese catalyst is typically in the 0.01 to $0.02 \mathrm{M}$ range, adding little waste to the stream being treated. Since the manganese is a catalyst it can be re-used until the liquid volume needs disposed for other reasons.

A Systems Engineering Evaluation for oxalate destruction during sludge treatment in 2009 rated this process highest of many, below those that use ultraviolet light (UV). ${ }^{\text {iii }}$ This method was considered to have the highest technical maturity (past large scale use) of all the methods including UV covered in the evaluation. The goal of the evaluation was to review oxalate destruction methods for tank cleaning, similar to the goal of the Bibler et al. summary.

Radke provided a partial literature search of the manganese-nitric process, collecting Russian and German work. ${ }^{\text {iv }}$ The reference included English translations of some of the literature. Within that set Mirkin and Koltunov studied nitric oxidation of oxalic acid at $97^{\circ} \mathrm{C}$. They found that the 
optimal reaction rate was seen when nitric acid concentration was around $1.5 \mathrm{M}(0.1$ to $6 \mathrm{M}$ tested). ${ }^{\mathrm{v}}$ They also found an induction period because the reaction was auto-catalytic. Nitrous acid was identified as the intermediate product that promoted oxidation.

The same process is described in a Japanese patent. ${ }^{\mathrm{vi}}$ That patent provides conditions for decomposing oxalic acid in a nitric acid solution containing a small amount of $\mathrm{Mn}$ (II). It claims that the process has no risk of explosion and is easily controlled.

Gray, Burney, and King included manganese-nitric acid oxidation of oxalate in their flowsheet for the purification of americium. ${ }^{\text {vii }}$ The proposed flowsheet called for processing in an acid evaporator where nitric acid would exceed $4 \mathrm{M}$ and manganese (II) ion concentration would be about 1 millimolar (mM). Time and oxalic reduction requirements were not given.

\subsubsection{Large Scale Applications of the Manganese(II)/Nitric Process}

Bibler reported that about 1000 pounds of oxalate was oxidized to carbon dioxide in 12 hours in an F-Canyon evaporator. ${ }^{\text {vii }}$ Feed solution to the evaporator contained $0.5 \mathrm{M}$ oxalic acid, $0.3 \mathrm{M}$ sodium nitrate, and $0.1 \mathrm{M}$ ferric nitrate. The evaporator pot was started with a partial fill of $4 \mathrm{M}$ nitric acid and $0.02 \mathrm{M}$ manganese nitrate. This solution was heated to boiling temperature and feeding commenced, slightly exceeding the boiloff rate. Feeding stopped when the pot was full and processing occurred at $100{ }^{\circ} \mathrm{C}$. Refluxing of the boil up was thought to return some nitric acid vapors to the pot. The overall process used about 2 moles of nitric acid per mole of oxalic acid destroyed. $99 \%$ of the oxalic acid was destroyed. The estimated reaction rate constant was 0.006 per minute.

Bibler reported a much larger project that oxidized 20 tons of oxalic acid in an F-Canyon evaporator. ${ }^{\text {ii }}$ The evaporator operated in semi-batch mode for operating cycles of typically 13 hours. Startup was similar to the work described above. The evaporator pot was first brought to temperature with 4000 liters of $4 \mathrm{M}$ nitric acid present along with $0.01 \mathrm{M}$ manganese (II). Feed solution was added at or slightly above the $2000 \mathrm{lb} /$ hour boiloff rate. The feed contained other metal ions including iron, aluminum, nickel, sodium, and mercury. Iron and aluminum have a mild inhibiting effect on kinetics. Temperature was typically $105{ }^{\circ} \mathrm{C}$ and the estimated kinetic rate constant was 0.014 per minute on average. About $99 \%$ oxalate destruction was realized, similar to the previous effort.

In the same report Bibler reported on a one-fifth scale semiworks project operated at TNX. This was the largest test that, because it was nonradioactive, gave the closest view of issues that might not be visible in radioactive plants. For example, running with concentrations of nitric acid below 2.5 M makes most efficient use of acid. Nitric oxide (NO) is the main nitrogen oxide gas evolved. The downside of low nitric inventory is that depletion of nitric acid in the reactor could cause the precipitation of any iron and aluminum present in the feed. When nitric acid depletes with oxalate present, metals oxalate precipitation is a possibility, and ability to consume the oxalate is lost as acid strength drops and oxalate precipitate forms. When nitric acid exceeds $3 \mathrm{M}$, it is consumed more quickly for each mole of oxalic acid degraded. Nitrogen dioxide is the main gas evolved along with carbon dioxide.

It was noted that the kinetic rate constant could change during batch or semibatch operation. While the manganese level would be constant, loss of nitric acid and changes in oxalate and soluble iron levels from precipitation would reduce the pseudo first order constant used in discussions of this process. The rate would be most stable if nitric acid strength is high. Acid economy and production of nitrogen dioxide would not be priorities in that choice of operation. 


\subsubsection{Kinetics Information for the Manganese(II)/Nitric Reaction}

Bibler and most other references report that the manganese-nitric oxidation of oxalic acid is first order with respect to manganese and oxalate concentrations. Rate constants are generally reported for the first-order reaction with respect to oxalate since the manganese catalyst is not consumed (no change in concentration) in the course of the reaction. At $100{ }^{\circ} \mathrm{C}$ Bibler reports a rate constant: ${ }^{\text {ii }}$

$$
\text { (first order rate constant, per minute) }=0.0017+0.91[\mathrm{Mn}+2]
$$

The expression reflects the fact that in the absence of the manganese catalyst the nitric acid still attacks the oxalic acid at a slow but measurable rate. This expression also is appropriate for cases of low sludge concentration, since iron inhibits the rate somewhat. The ratio of oxalate to ferric ion should be greater than 4 for equation (1) to be applied. At lower ratios (high iron) Bibler recommended the constant rate value of 0.008 per minute at $100{ }^{\circ} \mathrm{C}$.

Since much of the kinetics discussion in the literature tries to simplify the reaction rate to be first order in oxalic acid concentration, Figure 1 can be used to determine the impact of rate constant.

Figure 1. Time to Oxidize $95 \%$ Oxalate vs. Rate Constant

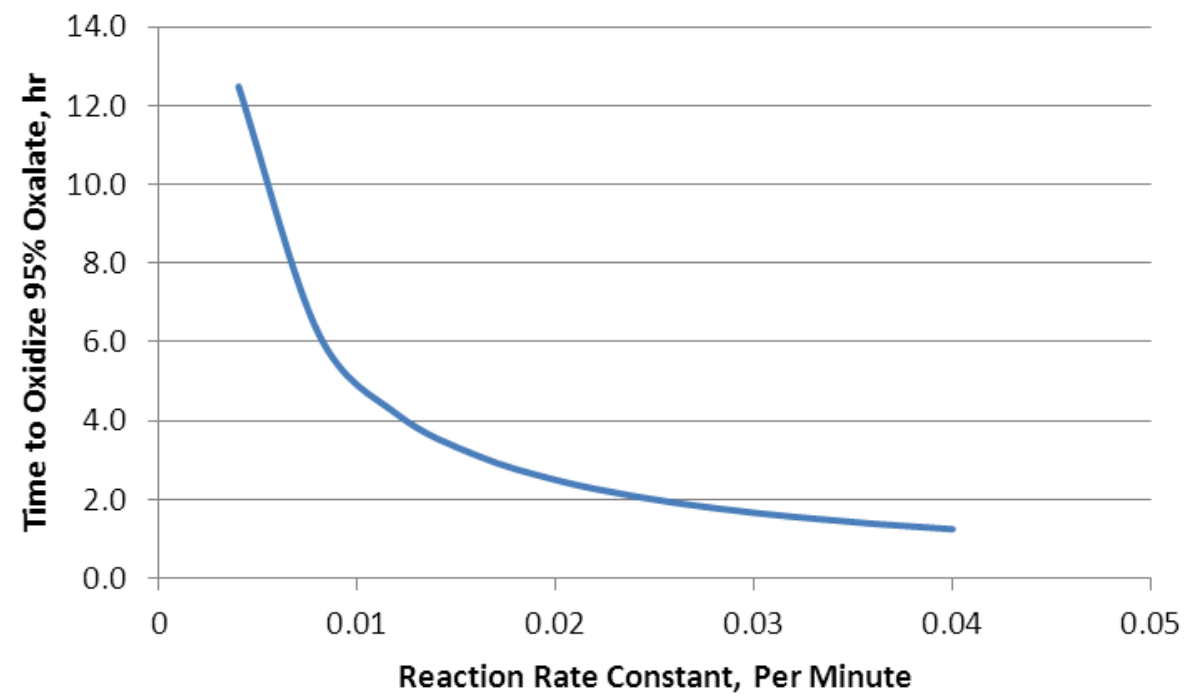

Temperature of the aqueous solution is a strong factor in the chemical kinetics. Bibler's study ${ }^{\mathrm{ii}}$ of the past data provided the following temperature correction for reaction rate:

$$
\text { (reaction rate)/(reference rate })=\exp ((25000 /(1.987) *[(1 . / \mathrm{K})-1 . /(\mathrm{K} \text { ref })])
$$

where $\mathrm{K}$ is temperature, in Kelvins, and $\mathrm{K}$ ref is the reference temperature, in Kelvins, where the reaction rate at reference conditions was observed. One example given was that if the reaction rate is known at a reference temperature of $90{ }^{\circ} \mathrm{C}(363.2 \mathrm{~K})$ then the reaction will proceed 2.6 times faster at $100{ }^{\circ} \mathrm{C}(373.2 \mathrm{~K})$. This shows that if acid strength was raised to raise the boiling point of the solution by even a few degrees $\mathrm{C}$, the higher temperature that would be made 
available would allow significantly higher reaction rates if needed. Figure 2 shows the effect of temperature when the reference temperature is $100^{\circ} \mathrm{C}$.

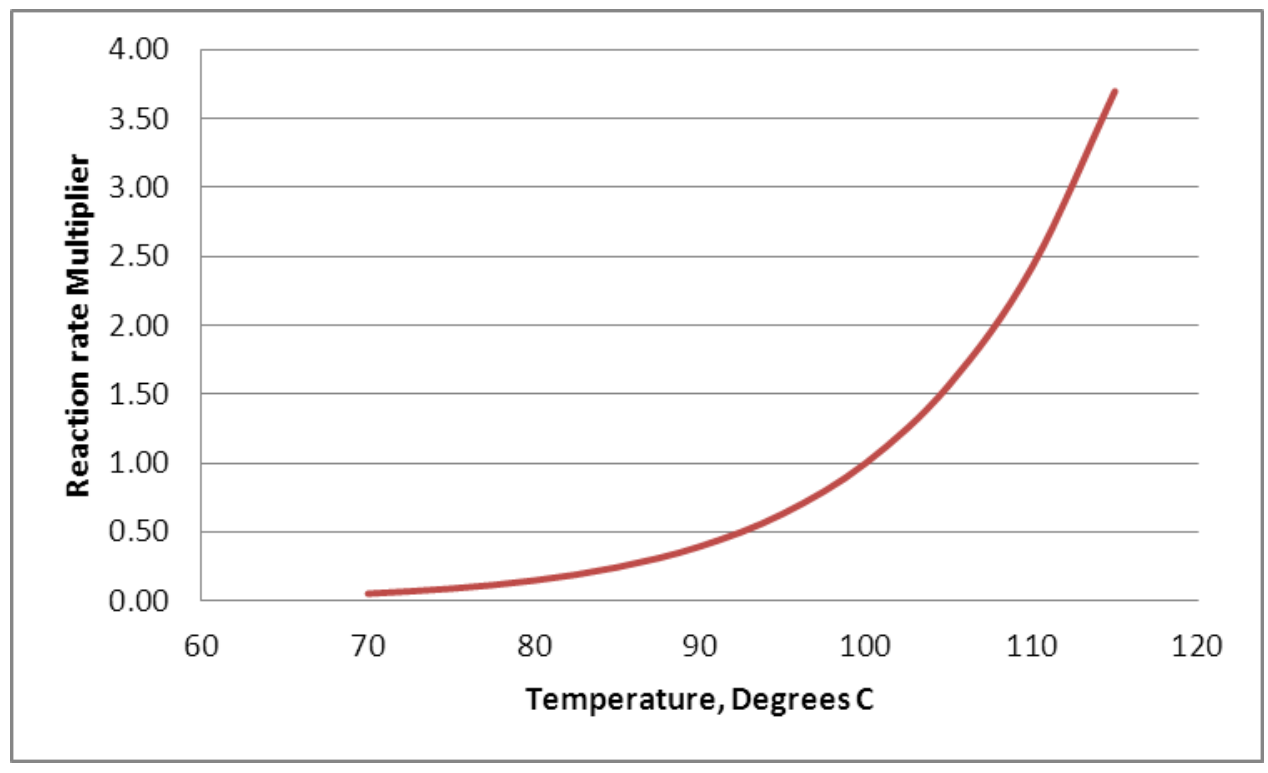

Figure 2. Effect of Temperature on Reaction Rate.

Equation 2 above uses a first order activation energy of 25,000 calories per mole, which was implied by the data. Additional support for this activation energy is found by Duke in his study of the kinetics of oxalate oxidation by manganese (III). ${ }^{\text {ix }}$ He pointed out that the rate limiting step is likely the breaking of the carbon-carbon bond in the oxalate molecule, and that this energy would be expected to be even higher without the catalytic action of manganese. Kubota on the other hand found the activation energy to be 18,600 calories per mole. ${ }^{\mathrm{x}}$ Kubota also found that the reaction is impractically slow below solution temperatures of $80^{\circ} \mathrm{C}$.

\subsection{Vanadium Catalyst using Nitric Acid}

Literature and patents support the use of vanadium rather than manganese as the catalyst for nitric acid oxidation of oxalic acid. Friedlin and co-workers reported reaction kinetic data with and without vanadium catalysis at $60{ }^{\circ} \mathrm{C}$ and above, and found an activation energy of 25,600 calories/mole. ${ }^{\mathrm{xi}}$ Similar to the manganese catalyzed reaction, they found that the oxidation of the oxalic acid was first order with respect to both vanadium and oxalate concentrations.

A French patent by Germain and Pasquiou shows that $0.1 \mathrm{M}$ oxalic acid or less can be oxidized in 1.5 to $13 \mathrm{M}$ nitric acid, where the soluble vanadate catalyst concentration is between $1 \mathrm{E}-5$ and 1E-2 M. ${ }^{\text {xii }}$ Temperature was typically at the solution boiling point.

\subsection{Nitric Acid without Catalysts}

Oxalic acid can be decomposed in nitric acid solution when other reagents are present. The reagents in this case are not catalytic and are consumed in the process. One example is the addition of organic chemicals that react readily with nitric acid, unlike oxalic acid. Japanese 
patent JP62-176593A teaches that additions of formic acid or sucrose to nitric acid will cause the decomposition of initially $0.1 \mathrm{M}$ oxalic acid. ${ }^{\text {xii }}$ The reaction intermediates from nitric attack on the formic acid or sucrose create side reactions with the oxalic acid to accomplish its destruction.

Vamplew and Singer studied the oxidation of oxalic acid by nitrous acid in the presence of nitric acid. $^{\text {xiv }}$ Nitrous acid is weak and unstable under acidic conditions, so the research presented difficulties in determination of its true concentration. Nitrous acid tends to dissociate into nitric acid with evolution of nitric oxide gas. In addition oxalic acid was found to be hard to decompose compared to other simple organic compounds like formic acid. This work found that oxalic acid was best decomposed in the $\mathrm{pH}$ range of 1 to 2, which is acidic but still allows for ionized oxalic anions to be present. Oxalate concentrations starting at 0.3 to $0.75 \mathrm{M}$ were found to be reduced by an order of magnitude at $45{ }^{\circ} \mathrm{C}$ within about 4 hours or less. The work concluded that molecular nitrous acid was the likely reagent attacking the ionized oxalate.

\section{4 $\underline{\text { Hydrogen Peroxide Including Nitric Acid }}$}

Use of nitric acid and hydrogen peroxide together was studied at Oak Ridge National Laboratory with and without copper or uranium catalysts. ${ }^{\mathrm{xv}}$ Those two selected catalysts were found to be ineffective. At $100{ }^{\circ} \mathrm{C}$ the oxalic acid oxidation progressed quickly such that oxalic acid half lives were less than 1 hour if $0.5 \mathrm{M}$ hydrogen peroxide was present initially. Nitric acid had a slightly positive effect on reaction rate in the range of neutral $\mathrm{pH}$ to $0.54 \mathrm{M}$ acid.

Chung and co-workers found that nitric acid had a mildly positive effect on kinetics (concentration to the 0.3 power) up to $2 \mathrm{M}$ nitric acid, and a much more favorable effect from 2 to $4 \mathrm{M}$ nitric acid. ${ }^{\mathrm{xvi}}$ The oxidation rate was also found to be first order in hydrogen peroxide concentration. Their work did not examine temperature effects as all work occurred at $90{ }^{\circ} \mathrm{C}$. They did examine the loss of hydrogen peroxide with no organic chemicals in nitric acid concentrations of 0 to $4 \mathrm{M}$, finding that more concentrated acid caused higher rates of peroxide decomposition. The peroxide half-life was approximately 1 hour in $4 \mathrm{M}$ nitric acid, and more than 2 hours at $2 \mathrm{M}$ acid or less. Their tests used hydrogen peroxide at $1 \mathrm{M}$. Oxalic acid at an initial concentration of $0.5 \mathrm{M}$ was more than $60 \%$ oxidized in one hour at $90{ }^{\circ} \mathrm{C}$.

\subsection{Hydrogen Peroxide and Fenton Chemistry}

The use of hydrogen peroxide and catalyst to oxidize organic chemicals has been known for more than a century. Fenton reported, for example, that ferrous sulfate acts as a catalyst rather than a reactant when mixed in small amounts with tartaric acid and hydrogen peroxide. ${ }^{\text {xii }}$ Since then hydrogen peroxide with an iron catalyst has been used widely for destruction of unwanted organic compounds. Kulik and co-workers, for example, demonstrated Fenton chemistry to destroy organic dyes at $\mathrm{pH} 3$ and $20{ }^{\circ} \mathrm{C}$. ${ }^{\text {xiii }}$ Dye color indicated about 95\% destruction for 24 hour treatment tests. The work was in support of industrial waste water treatment. Kelley and coworkers reported the use of Fenton chemistry to help in the treatment of waste polyaromatic hydrocarbons. ${ }^{\text {xix }}$ That report in addition provides many other references for the use of Fenton oxidation in organic waste treatment.

Walton and Graham reported difficulties in using iron/hydrogen peroxide to oxidize oxalic acid. ${ }^{\mathrm{xx}}$ Oxalic acid was harder to process than was formic, malic, tartaric, and other organic chemicals. One problem was that oxalate complexes the iron catalyst in a way that inactivates it. The problem could be reduced by adding iron in molar excess of oxalate so that non-complexed iron 
was available for catalysis. However, no more than one third of available oxalic acid was oxidized after 50 hours at $25{ }^{\circ} \mathrm{C}$. Performing the reaction at elevated temperatures caused nonproductive decomposition (loss) of the hydrogen peroxide. Copper catalyzed the peroxide decomposition of some organic materials outside of oxalic acid, but the copper would precipitate with oxalate so that soluble copper was not available. Hay also mentioned that complexation between oxalic acid and metals would impede oxidation of the acid. ${ }^{\mathrm{xxi}}$ He suggested though that specific study of this process with scoping tests might be justified.

\subsection{Photochemical Methods}

Jeong and Yoon studied photochemical destruction of a common organic herbicide in the presence of soluble ferric ion with and without oxalate. ${ }^{\text {xxii }}$ The iron oxalate complex was found to be more effective in oxidizing the herbicide than iron alone. The reaction rate was optimal at $\mathrm{pH}$ 5 to 6 , where a range of 1 to 7 was studied. Hydrogen peroxide at $1 \mathrm{E}-4$ to $1 \mathrm{E}-3 \mathrm{M}$ initial concentrations were found to remove the induction period for the oxidation reaction, but higher concentrations were found to impede the reaction rate. Half-lives for the herbicide were less than 20 minutes in this study, but the initial concentration was very low, being $1 \mathrm{E}-5 \mathrm{M}$.

\subsection{Other Methods}

Permanganate has been used widely to titrate oxalate (and vice versa), resulting in the oxidation to water, manganese (II), and carbon dioxide. ${ }^{\text {xiii }}$ The reaction is catalyzed (and auto-catalyzed) by manganese(II). It requires heating to more than $50{ }^{\circ} \mathrm{C}$ for an effective reaction rate. This reaction generates large quantities of solid $\mathrm{MnO}_{2}$ as a by-product.

Dukkanci and Gunduz reported on degradation of aqueous oxalic acid using ultrasonic energy. ${ }^{\text {xiv }}$ They found that oxalic acid is relatively hard to attack and that an ultrasonic process is unlikely to do better than catalyzed wet air oxidation, photocatalytic oxidation, or ozone treatment combined with a heterogeneous catalyst. Their range of testing included the presence of sodium chloride, hydrogen peroxide, and air sparging in separate tests. They did not find an ultrasonic process that stood out as being practical.

Shende and Mahajani studied wet air oxidation of glyoxalic and oxalic acids because these and other simple organic acids like acetic are often final intermediates when wet air oxidation is applied to industrial and municipal wastes. ${ }^{\mathrm{xxv}}$ Oxalic acid was found to be harder to oxidize than glyoxalic acid. The wet air process involved temperatures of 120 to $245{ }^{\circ} \mathrm{C}$ and oxygen partial pressure of $0.345-1.38 \mathrm{MPa}$ (50 to $200 \mathrm{psi}$ ) with and without a copper sulfate catalyst. The kinetic activation energy for oxidizing oxalic acid was found to be $31.9 \mathrm{kcal} / \mathrm{mol}$. The degradation of oxalic acid led to carbon dioxide without a formic acid intermediate. The copper catalyst was found to be very effective in enhancing the reaction rate.

\subsection{Post Filtration Precipitation of Plutonium Oxalate}

The HB Line process precipitates plutonium with an oxalic acid solution followed by a digestion period and filtration. These parts of the process will be performed at $50{ }^{\circ} \mathrm{C}$. A small amount of plutonium will be carried through the filter by at least one of three mechanisms: dissolved plutonium oxalate, fines penetration, and supersaturation. The filtrate will naturally cool downstream, causing precipitation of some of the soluble plutonium oxalate. The discussion below addresses solubility of solids in the filtrate. 


\subsection{Composition of the Filtrate}

Table 1 provides ranges of composition of the filtrate relevant to this process. Evaluation of post precipitation would thus be reasonable with nitric acid concentrations between 1.5 and $4.5 \mathrm{M}$, oxalic acid up to $0.15 \mathrm{M}$, and plutonium of 1 to $2 \mathrm{mM}$ (239 to $478 \mathrm{mg} / \mathrm{L}$ ).

Table 1. Filtrate Composition Ranges

\begin{tabular}{|c|c|c|c|}
\hline Reference & $\begin{array}{l}\text { Nitric Acid } \\
\text { Range, } M\end{array}$ & $\begin{array}{l}\text { Oxalic Acid } \\
\text { Range, } M\end{array}$ & $\begin{array}{c}\text { Plutonium } \\
\text { Concentration, } \\
\text { mg/L }\end{array}$ \\
\hline $\begin{array}{l}\text { TTR NMMD-HTS-2011-3175 } \\
\text { (reference i) }\end{array}$ & 1.5 to 4.0 & Maximum 0.15 & Maximum 200 \\
\hline R. H. Smith ${ }^{\mathrm{xxvi}}$ & 1.46 used & 0.145 used & Maximum 410 \\
\hline Facer and Harmon ${ }^{\text {xxvii }}$ & $\begin{array}{l}1.5 \text { to } 4.5 \text { best at } \\
50^{\circ} \mathrm{C}\end{array}$ & 0.04 to 0.16 & $*$ \\
\hline
\end{tabular}

* The wide range of test conditions and chemistry necessitates reporting a very wide range here.

Facer and Harmon studied a wide range of temperatures, acid concentrations, and chemistry, and sometimes saw several grams per liter of plutonium in filtrate. ${ }^{\text {xxvi }}$ Most of their studies saw well under $500 \mathrm{mg} / \mathrm{L}$ plutonium. Major differences in most of their cases compared to the planned $\mathrm{H}$ Canyon process include hydrogen peroxide addition to ensure that plutonium was at $4+$ valence, and cooling of the precipitate slurry down to as low as $5{ }^{\circ} \mathrm{C}$ before filtration. They studied use of nitric acid up to $12 \mathrm{M}$ in the precipitation process.

Hoyt studied the plutonium (IV) oxalate precipitation process under a wide range of conditions. ${ }^{\text {xviii }}$ His report includes a review of literature databases for plutonium oxalate solubility in concentrated acid. He found that plutonium oxalate was more soluble at $50{ }^{\circ} \mathrm{C}$ than at $27^{\circ} \mathrm{C}$. The data are only shown on a log graph and it appears that solubility at the higher temperature is about twice that of the cooler solution. Hoyt also indicated precipitate rheology problems (with slurry gelling) above $4 \mathrm{M}$ nitric acid. Precipitate plutonium concentrations are much higher than those of filtrate, and thus problems with filtrate and high ionic strength are less likely.

Hoyt also examined precipitate particle size, formation rate, and morphology in detail as a function of plutonium to oxalate mole ratio. Particle morphology and growth rate fluctuations dictated that oxalate level should exceed the stoichiometric 2:1 oxalate:plutonium reacting mole ratio. Failure to exceed the 2:1 mole ratio caused crystal growth and buildup on all internal surfaces of the precipitation equipment. At least $1 / 4$ inch of buildup was found inside the equipment after only four hours of operation.

Table 2 shows temperature/solubility data from Table XV of Facer and Harmon. ${ }^{\text {xxvi }}$ The multiple values come from replicated tests. It is clear that plutonium oxalate becomes more soluble with increased temperature. Average solubility at $50{ }^{\circ} \mathrm{C}$ appears to be twice that at $25{ }^{\circ} \mathrm{C}$. This means that half the soluble plutonium oxalate passing through a filter at $50{ }^{\circ} \mathrm{C}$ may post-precipitate when the filtrate cools to room temperature. The data also show that filtration at temperatures higher than $50{ }^{\circ} \mathrm{C}$ will lead to substantial losses and post-filtration precipitation. 
SRNL-STI-2012-00003

Revision 0

Table 2. Plutonium Concentration from Oxalate Filtration ${ }^{\mathrm{xxv}}$

\begin{tabular}{|c|c|}
\hline Filtration Temperature & $\begin{array}{c}\text { Plutonium Concentration in } \\
\text { Filtrate, } \mathbf{~ m g} / \mathbf{L}\end{array}$ \\
\hline $25^{\circ} \mathrm{C}$ & $27,31,31,21$ \\
\hline $50^{\circ} \mathrm{C}$ & 49,82 \\
\hline $75^{\circ} \mathrm{C}$ & 423,1163 \\
\hline
\end{tabular}

\subsection{Concentrated Nitric Acid}

The works cited in this section support a strategy of increasing nitric acid level in filtrate so that a ratio of [free oxalate]/[square of hydrogen ion concentration] is reduced. The logic for the ratio is that oxalate complexed with plutonium would have to release two protons. The equilibrium is shown below, where $\mathrm{n}$ is charge of soluble species:

$$
\left.[\text { Pu species }]^{(\mathrm{n})}+\mathrm{C}_{2} \mathrm{H}_{2} \mathrm{O}_{4}<=>\text { [new Pu species with } \mathrm{C}_{2} \mathrm{O}_{4}^{-2}\right]^{(\mathrm{n}-2)}+2 \mathrm{H}^{+}
$$

Oxalic acid in solution is certainly fully protonated given the high nitric acid levels. Precipitate filtrate would have a range of 1.5 to $4 \mathrm{M}$ nitric acid and approximately $0.1 \mathrm{M}$ oxalate, so increasing nitric acid concentration would reduce the ratio and increase solubility. Dilution of the solution to reduce oxalate concentration would also increase solubility.

Reas studied the chemical system of plutonium (IV) with nitric and oxalic acids with a view to identify soluble species. ${ }^{\text {xxix }} \mathrm{He}$ used spectroscopic evidence to identify complexes of plutonium(IV) and one, two, or three oxalate dianions. The soluble species were thus $+2,0$, or -2 in charge respectively. The data supported these identifications versus those where oxalate was singly protonated either in solution or coordinated with plutonium. His experiments focused on $\mathrm{Pu}(\mathrm{IV})$ in $0.75 \mathrm{M}$ nitric acid and varying strengths of oxalate.

Mandleburg and co-workers extended the range of nitric acid level (0.5 to $3.52 \mathrm{M}$ ) along with varying oxalate level from zero to $0.5 \mathrm{M}^{\mathrm{xxx}}$ Figure 3 shows the Reas and Mandleburg data plotted versus the ratio mentioned above. The figure indicates that plutonium oxalate solubility goes through a minimum in this coordinate system and that increasing nitric acid levels (or reducing free oxalate levels) will increase the total solubility of plutonium, including anionic complexes.

The minimum solubility is near $\mathrm{Fp}=$ [oxalate]/[square of hydrogen ion concentration] $=0.01$. Process operation of $2 \mathrm{M}$ nitric acid and $0.1 \mathrm{M}$ oxalic acid would not be far from this condition on the log graph, but increasing acid strength to $10 \mathrm{M}$ in filtrate would lead to $\mathrm{Fp}=0.001$ or less, since increasing acid strength would dilute the oxalate contained in the filtrate. Operation of the precipitation process near the minimum (pre-filtration) is desired for minimizing plutonium losses. 
SRNL-STI-2012-00003

Revision 0

Figure 3. Plutonium Oxalate Solubility Data

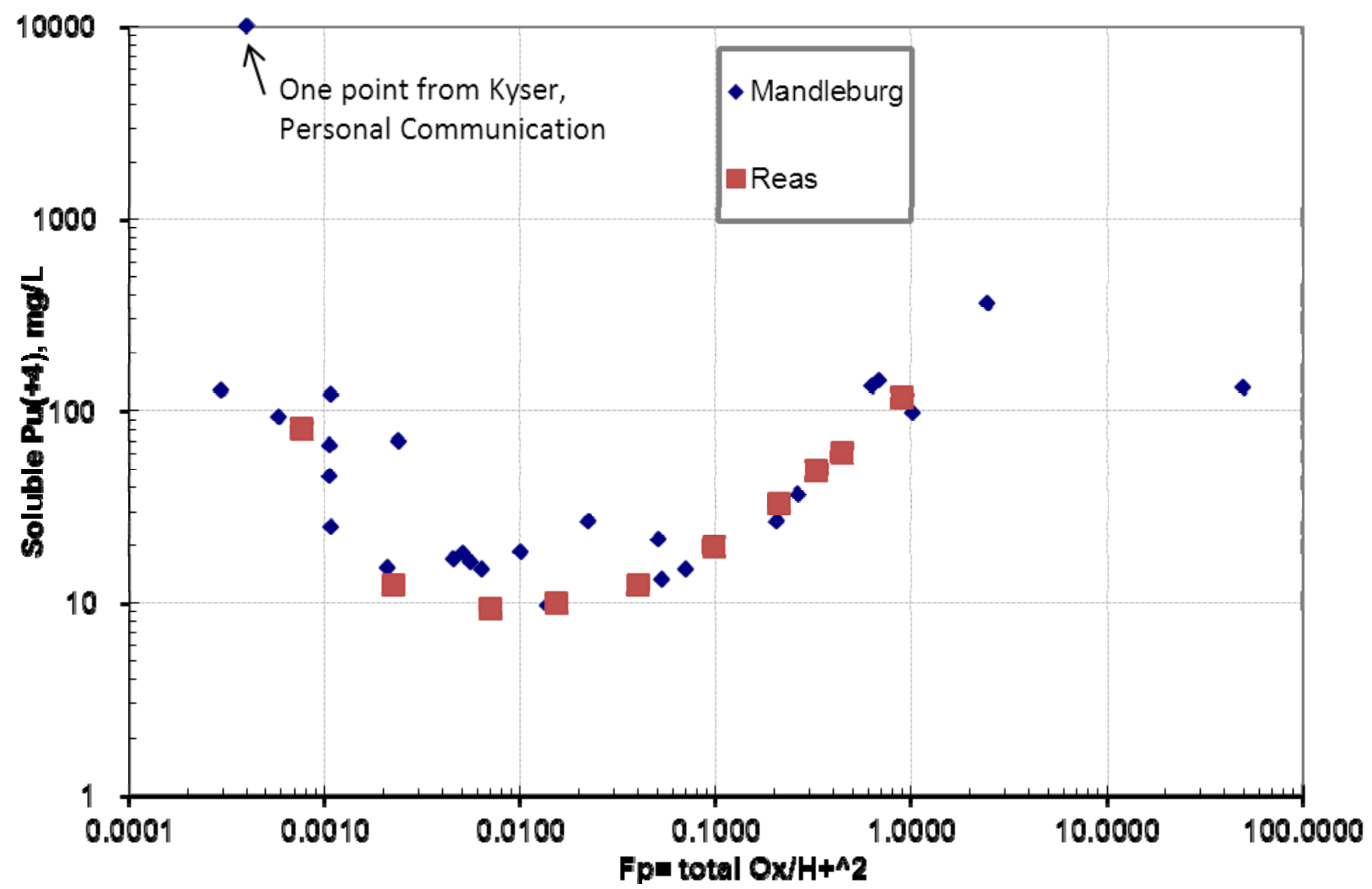

Rao and co-workers used slow hydrolysis of an oxalate ester to obtain solubility data for plutonium(IV) oxalate in nitric acid. ${ }^{\mathrm{xxx}}$ Their data were only shown in graphical form and were generally higher than the Mandleburg data. The range of their data mainly showed the decline in plutonium oxalate solubility as nitric acid concentration increased from near zero levels to around $4 \mathrm{M}$.

Gel'man and co-authors provided a solubility equation for plutonium oxalate dihydrate in perchloric acid: ${ }^{\text {xxii }}$

$$
\text { Solubility, } \mathrm{M}=3.2 \mathrm{E}-5+1 \mathrm{E}-11 *\left[\mathrm{H}^{+}\right]^{4} /\left[\mathrm{H}_{2} \mathrm{C}_{2} \mathrm{O}_{4}\right]^{2}
$$

While the equation was developed from perchloric rather than nitric acids it predicts an increase in solubility with acid strength. Tables 3 and 4 provide calculated results from the Reas equation and the Gel'man equation. Values were converted to $\mathrm{mg} / \mathrm{L}$ for comparison with other figures and tables in this report. The values between Tables 3 and 4 are not much different except at low oxalate level. The low level was included for consideration of oxalate sequestration (see Section 3.3, following this one). The data shows that the effect of concentrated nitric acid alone perhaps doubles the solubility of plutonium as oxalate, but this would not help with solids if the total plutonium concentration is hundreds of $\mathrm{mg} / \mathrm{L}$. However, reduction of oxalate concentration shows a dramatic improvement (increase) in plutonium solubility. 
Table 3. Plutonium Solubility as Oxalate, mg/L, predicted by Reas Work

\begin{tabular}{||c|r|r|r|r||}
\hline $\begin{array}{c}\text { Nitric Acid } \\
\text { Strength, M }\end{array}$ & \multicolumn{4}{|c|}{ Oxalic acid Concentration, M } \\
\hline & 0.005 & 0.05 & 0.1 & 0.15 \\
\hline 2 & 13. & 10. & 12. & 14. \\
\hline 4 & 31. & 10. & 10. & 10. \\
\hline 6 & 61. & 13. & 10. & 10. \\
\hline 8 & 102. & 17. & 12. & 11. \\
\hline 10 & 156. & 22. & 15. & 12. \\
\hline 12 & 221. & 29. & 18. & 15. \\
\hline
\end{tabular}

Table 4. Plutonium Solubility as Oxalate, mg/L, predicted by Gel'man

\begin{tabular}{|c|r|r|r|r||}
\hline $\begin{array}{c}\text { Perchloric } \\
\text { Acid } \\
\text { Strength, M }\end{array}$ & \multicolumn{5}{|c||}{ Oxalic acid Concentration, M } \\
\hline & 0.005 & 0.05 & 0.1 & 0.15 \\
\hline 2 & 9. & 8. & 8. & 8. \\
\hline 4 & 32. & 8. & 8. & 8. \\
\hline 6 & 132. & 9. & 8. & 8. \\
\hline 8 & 399. & 12. & 9. & 8. \\
\hline 10 & 964. & 17. & 10. & 9. \\
\hline 12 & 1990. & 28. & 13. & 10. \\
\hline
\end{tabular}

Hoyt provided a comparison of plutonium oxalate solubility work including original data from his work. ${ }^{\text {xxvii }}$ He confirmed that solubility goes through a minimum as a function of nitric acid concentration. The minimum solubility increases versus nitric acid concentration with increasing free oxalate concentration.

Use of excess nitric acid may lead to downstream effects. Harmon warned that $8 \mathrm{M}$ nitric acid might create a gum-like residue from plutonium oxalate and Hoyt found gel formation (prefiltration) at $4 \mathrm{M}$ or more concentrated nitric acid at precipitator levels of plutonium.(xxvi, xxvii) Boiling of plutonium solution in an evaporator may lead to the more highly oxidized Pu(VI). While this behavior does not pose a solubility problem, it needs to be accounted for if the plutonium level is monitored by some means that depends on oxidation state. Spectroscopic means, for example, would need to be calibrated for all anticipated oxidation states of soluble plutonium.

\subsection{Complexation of Oxalate}

Reduction of the chemical activity of oxalate is a means of increasing plutonium solubility in this system where excess nitric acid is present to allow formation of plutonium(IV) nitrate. Trivalent iron or aluminum metal ions are known to form soluble complexes with oxalate, and such complexation would reduce the chemical activity of oxalate. 
Ferric ion (iron (III)) was considered in complex stability calculations to determine that iron(III) addition is effective in sequestering oxalate. A spreadsheet with the manual calculations used stability constants from Martel for oxalate-hydrogen and oxalate-ferric ion. ${ }^{\text {xxxii }}$ Results in Table 5 below show that added ferric ion efficiently sequesters oxalate, with better efficiency at the lower acid strength. If ferric ion exceeds oxalate concentration $(0.15 \mathrm{M}$ vs. $0.05 \mathrm{M})$ then $96 \%$ of the oxalate is sequestered. When oxalate exceeds ferric concentration then most of the ferric works usefully to complex oxalate, but it is depleted in the process. Since ferric oxalate is very soluble it would boost plutonium solubility per Tables 3 and 4, where only remaining free oxalate is still available to reduce plutonium solubility. This strategy would reduce free oxalate by an order of magnitude in practice.

Table 5. Percent Oxalate Sequestered Under Varied Conditions

\begin{tabular}{||c|c|c|c||}
\hline $\begin{array}{c}\text { Nitric Acid } \\
\text { Concentration }\end{array}$ & $\begin{array}{c}\text { Total Ferric Ion }= \\
\mathbf{0 . 0 5} \mathbf{M}\end{array}$ & $\begin{array}{c}\text { Total Ferric Ion }= \\
\mathbf{0 . 1 5} \mathbf{~ M}\end{array}$ \\
\hline \multirow{3}{*}{2 Molar } & $\begin{array}{c}\text { Total Oxalate } \\
\mathbf{0 . 0 5} \mathbf{M}\end{array}$ & $0.038 \mathrm{M}(75 \%)$ & $0.048 \mathrm{M}(96 \%)$ \\
\cline { 2 - 4 } & $\begin{array}{c}\text { Total Oxalate } \\
\mathbf{0 . 1 5} \mathbf{M}\end{array}$ & $0.048 \mathrm{M}(32 \%)$ & $0.127 \mathrm{M}(85 \%)$ \\
\hline \multirow{3}{*}{4 Molar } & $\begin{array}{c}\text { Total Oxalate } \\
\mathbf{0 . 0 5} \mathbf{M}\end{array}$ & $0.0286 \mathrm{M}(57 \%)$ & $0.0435 \mathrm{M}(87 \%)$ \\
\cline { 2 - 4 } & $\begin{array}{c}\text { Total Oxalate } \\
\mathbf{0 . 1 5} \mathbf{M}\end{array}$ & $0.0432 \mathrm{M}(29 \%)$ & $0.108 \mathrm{M}(72 \%)$ \\
\hline
\end{tabular}

If the ferric addition strategy to sequester oxalate were applied to a concentrated acid solution, effectiveness was found to be more challenged. Under the assumption of $10 \mathrm{M}$ nitric acid, 0.03 $\mathrm{M}$ oxalate (concentration reduced by dilution with reagent acid), and $0.39 \mathrm{M}$ iron (III), $75 \%$ of the oxalate is sequestered.

Separately OLI Software (OLI Systems, Morris Plains, NJ) was used to evaluate some of the conditions in Table 5. It always found greater than $98 \%$ sequestration, even at $4 \mathrm{M}$ nitric acid, supporting the viability of this strategy.

\subsection{Complexant Addition to Compete for Plutonium (IV)}

Reduction of the chemical activity of plutonium(IV) in an oxalate solution will reduce the tendency for precipitation. Addition of soluble complexing species to compete with oxalate was investigated by calculation. Gel'man listed acids forming polyanions that complete for $\mathrm{Pu}(\mathrm{IV})$ and provided the following series: ${ }^{\mathrm{xxx}}$

$$
\text { Carbonate }>\text { EDTA }>\text { hydrogen phosphate }>\text { tartrate }>\text { citrate }>\text { oxalate }>\text { sulfate }
$$

Stability constants are provided in the reference. Species to the left of oxalate would provide the strongest competition, though even sulfate would help move the solution away from plutonium oxalate precipitation. While carbonate is shown as best in the series, it is impractical because it would be driven off as carbon dioxide in concentrated acid systems like this one. Organic 
complexants were considered in the current case where the solution is being sent to an organic oxidation process, removing downstream problems that may be caused by the additives.

Citric, tartaric, sulfuric, and ethylenediaminetetraacetic acids (EDTA) were considered for use in calculations for this strategy. In the course of examining these options the EDTA was discounted because it is not soluble to an appreciable extent in aqueous solutions. Its use would likely lead to solids in the H-Canyon tank system, which is not acceptable. It can also lead to hydrogen production due to radiolysis in the tank farms as happened at Hanford. The same is true for citric and tartaric acids.

Table 6 shows the aqueous solubilties of the complexants considered. These data would be useful in planning to make reagent solutions for the plant. It appears that aqueous addition of EDTA may be impractical due to the need to add much water concurrently. ${ }^{\text {xxiv }}$ EDTA solubility increases in nitric acid, reaching $0.012 \mathrm{M}$ at $1 \mathrm{M}$ nitric acid at $25^{\circ} \mathrm{C}$ and an ionic strength of 1 . $^{\mathrm{xxv}}$ Both acid strength and ionic strength boost its solubility.

Table 6. Aqueous Solubility of Organic Complexants at $20^{\circ} \mathrm{C}$

\begin{tabular}{|c|c|c|c||}
\hline $\begin{array}{c}\text { Complexing } \\
\text { Chemical }\end{array}$ & $\begin{array}{c}\text { Solution Density, } \\
\text { g/mL, at (Molarity) }\end{array}$ & $\begin{array}{c}\text { Grams/100 mL } \\
\text { Solution }\end{array}$ & Solubility Limit \\
\hline Citric Acid & $1.13(1.77 \mathrm{M})$ & 159 & $2.2 \mathrm{M}$ \\
\hline Tartaric Acid & $1.32(5.1 \mathrm{M})$ & 239 & $5.1 \mathrm{M}$ \\
\hline EDTA & $\sim 1.0$ (low solubility) & 0.05 & $0.0017 \mathrm{M}$ \\
\hline
\end{tabular}

Tartaric acid is easy to add, but stability constant data seem to indicate that it will not sequester $\mathrm{Pu}(\mathrm{IV})$ when acid is at molar levels. Gel'man displays a value for the $\mathrm{Pu}(\mathrm{IV})$ 6-tartrate complex, but the stability of such a large complex is too low to help sequester Pu(IV) in molar acid.

The mono-complex of Pu(IV) and citrate has been studied by several methods and values for it and the dicitrate complex are provided by Cleveland. ${ }^{\text {xxvi }}$ Approximate values of $1 \mathrm{E}+15$ and $6.9 \mathrm{E}+29$ for the mono- and di- complexes were used in a spreadsheet. $\mathrm{Pu}(\mathrm{IV})$ nitrate, oxalate, and citrate complexation calculations showed that less than $1 \%$ of the plutonium was effectively complexed. Stability constants for plutonium sulfate complexes from Fardy and Pearson were used to calculate results for that strategy, and plutonium sequestration was not practical in that case either. ${ }^{\text {xxvii }}$ This behavior was true for the acid ranges discussed above, so this strategy is not viable.

\subsection{Solubility of Gadolinium Oxalate in Nitric Acid}

Gadolinium (or boron) will likely be present in the process liquids as a neutron poison. Table 7 shows data by Sarver and Brinton on the solubility of Gd in nitric acid/oxalate systems at $25{ }^{\circ} \mathrm{C}$. ${ }^{\mathrm{xx} x \mathrm{iii}}$ The data in the third column is expressed as mass of anhydrous $\mathrm{Gd}_{2}\left(\mathrm{C}_{2} \mathrm{O}_{4}\right)_{3}$. The reference did not provide solution density, so interpolations of nitric acid specific gravities from the CRC handbook were used to calculate mass concentrations of gadolinium (last column). ${ }^{\text {xxix }}$ Increasing concentration of the acid at constant oxalate level boosts solubility. 
Table 7. Solubility of Gadolinium Oxalate in Nitric Acid ${ }^{\mathrm{xx} x \mathrm{iii}}$

\begin{tabular}{|c|c|c|c|c||}
\hline $\begin{array}{c}\text { Normality of } \\
\text { Nitric Acid }\end{array}$ & $\begin{array}{c}\text { Normality of } \\
\text { Oxalate }\end{array}$ & $\begin{array}{c}\text { Grams Gd- } \\
\text { Oxalate per } \\
\text { 100 g Solution }\end{array}$ & $\begin{array}{c}\text { Estimated } \\
\text { specific } \\
\text { gravity** }\end{array}$ & $\begin{array}{c}\text { Calculated } \\
\text { Grams per } \\
\text { liter Gd }\end{array}$ \\
\hline 0.248 & $*$ & 0.0219 & 1.01 & 0.120 \\
\hline 1.992 & $*$ & 0.2785 & 1.07 & 1.62 \\
\hline 4.054 & $*$ & 0.9032 & 1.13 & 5.55 \\
\hline 2.00 & 0.05 & 0.0768 & 1.07 & 0.45 \\
\hline 3.03 & 0.05 & 0.2813 & 1.10 & 1.68 \\
\hline 4.00 & 0.05 & 0.5498 & 1.13 & 3.38 \\
\hline 2.00 & 0.25 & 0.0128 & 1.07 & 0.074 \\
\hline 3.03 & 0.25 & 0.0463 & 1.10 & 0.28 \\
\hline 4.00 & 0.25 & 0.1397 & 1.13 & 0.86 \\
\hline 4.00 & saturated & 0.0383 & 1.13 & 0.24 \\
\hline 6.00 & saturated & 0.1227 & 1.20 & 0.80 \\
\hline
\end{tabular}

* No value given, so gadolinium oxalate may be the only source of oxalate for these conditions **Based on normality of nitric acid in solution, provided by ref. xxxix, not by Sarver

\subsection{Conclusions}

The manganese (II) catalyzed nitric acid process at near boiling temperatures is a welldocumented and effective means of oxidizing oxalate in solution. It is recommended for use in $\mathrm{H}$ Canyon. It requires near boiling temperatures that would be provided by an evaporator.

Prevention of post-filtration precipitation of plutonium oxalate can be accomplished by the combination of increased nitric acid concentration plus addition of ferric ion. The net effect is to sequester oxalate while at the same time making nitric acid available to boost plutonium (IV) solubility. It does not appear that post-filtration precipitation can also be avoided by adding millimolar amounts of organic complexing agents that sequester plutonium (IV).

Note that in all cases of chemical treatment to avoid precipitation, downstream effects must be considered. The nitric/ferric strategy would increase the amount of downstream waste iron. The evaporator would be used to recover nitric acid. The complexant strategy requires effective organic destruction downstream so that complexing agents do not boost actinide solubilities and interfere with downstream processes or waste treatment. 


\subsection{Recommendations}

This work indicates confirmatory lab testing for both oxalate destruction and prevention of plutonium oxalate precipitate in filtrate.

\subsection{Oxalate Destruction}

Nonradioactive testing would precede one or two plutonium-bearing runs to confirm that the reaction rate for oxalate oxidation is within expectations. Table 8 provides varied conditions to be considered. Since ionic strength would exceed $1 \mathrm{M}$, work at $100{ }^{\circ} \mathrm{C}$ would be conservative but effective in the confirmation (higher ionic strength allows higher operating temperature before boiling commences). Concentrated acid and the presence of iron may slow the reaction rate, but again, temperature is the strongest control that can be used to boost the rate. Manganese (II) at two levels is proposed. Initial oxalic acid concentration would be $0.1 \mathrm{M}$. Sampling would be every 15 minutes in the first two hours, then one hour for the next six hours. Oxalate would be measured by IC or by permanganate titration. Data would provide reaction rate constants for each condition. Any impurities of interest including neutron poisons would be added at the same concentration for all tests.

Table 8. Suggested Conditions for Oxalate Oxidation

\begin{tabular}{|c|c|c|}
\hline $\begin{array}{c}\text { Nitric Acid } \\
\text { Molarity }\end{array}$ & Iron (III) Molarity & $\begin{array}{c}\text { Manganese } \\
\text { Molarity }\end{array}$ \\
\hline 4 & 0 & 0.005 and 0.02 \\
\hline 4 & 0.3 & 0.005 and 0.02 \\
\hline 10 & 0 & 0.005 and 0.02 \\
\hline 10 & 0.3 & 0.005 and 0.02 \\
\hline
\end{tabular}

A set of duplicated tests that includes plutonium and the conditions agreed upon from results of nonradioactive runs would complete the confirmation.

\subsection{Example Calculation for Rate of Oxalate Destruction}

Lab scale results are to be compared with expectations for reaction rate. An example would be 8 $\mathrm{M}$ nitric acid in the evaporator pot with $0.01 \mathrm{M} \mathrm{Mn(II)}$ and a goal of $99.9 \%$ oxalate destruction. The boiling point for $8 \mathrm{M}$ nitric acid is just over $110{ }^{\circ} \mathrm{C}$ at one atmosphere absolute pressure, and its density is $1.25 \mathrm{~g} / \mathrm{mL}^{\mathrm{xl}}$ Section 2.1 .2 shows that at $100{ }^{\circ} \mathrm{C}$ the rate constant is 0.008 per minute if much iron is present and 0.0108 per minute (per equation 1 ) if iron is not present. Table 9 below provides the time to complete the work at 100 and $110{ }^{\circ} \mathrm{C}$, which are practical temperatures not limited by (and are below) the solution boiling point. Equation 2 of Section 2.1.2 was used for the temperature adjustment away from $100{ }^{\circ} \mathrm{C}$. In all cases the processing time for $99.9 \%$ oxalate destruction is practical. 
SRNL-STI-2012-00003

Revision 0

Table 9. Calculated Time Needed for $99.9 \%$ Oxalate Destruction

\begin{tabular}{|c|c|c|c|}
\hline Temperature, ${ }^{\circ} \mathrm{C}$ & Iron Present & $\begin{array}{l}\text { Kinetic Rate } \\
\text { Constant, per } \\
\text { minute }\end{array}$ & $\begin{array}{l}\text { Time for 99.9\% Oxalate } \\
\text { Destruction, Hours }\end{array}$ \\
\hline 100 & Yes & 0.008 & 14.4 \\
\hline 100 & No & 0.0108 & 10.5 \\
\hline 110 & Yes & 0.0193 & 6.0 \\
\hline 110 & No & 0.0261 & 4.4 \\
\hline
\end{tabular}

\subsection{Plutonium Solubility Tests}

A radioactive filtrate with trace plutonium oxalate solids would be used in testing where the filtrate is added to warm reagent solution, cooled over time, and filtered. Filtration with a fine filter such as 0.2 micron would remove any undissolved plutonium solids. This approach would allow detection of undissolved plutonium-bearing solids. Comparison of known plutonium content with that found in filtrate would indicate level of success in preventing precipitation. A

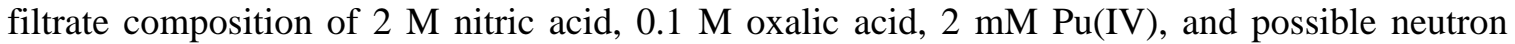
poison is suggested. This filtrate would be above the saturation level of plutonium oxalate, and filtration would show a reduction of plutonium in the filtrate.

Reagent solutions would include ferric nitrate and nitric acid. Since this test adds solidscontaining filtrate to the reagent, dissolution of the solids would be indicated by plutonium concentration in the test filtrate sample.

\subsection{References}

${ }^{i}$ Clifton, W. H., "Flowsheet Evaluation for Oxalate Kill in H-Canyon", Technical Task Request NMMDHTS-2011-3175, November 03, 2011.

${ }^{i i}$ Bibler, N. E. Hoisington, J. E., and Holtzscheiter, E. W., "Technical Data Summary Destruction of Oxalic Acid by Manganese Catalyzed Nitric Acid Reaction,” DPSTD-80-36, March, 1981.

iii Martino, C. J., "Evaluation of Alternative Chemical Cleaning and Enhanced Chemical Cleaning Methods”, SRNL-L3100-2009-00118, rev. 0, June 29, 2009.

${ }^{\text {iv }}$ Radke, J. H., "Oxidation of Oxalic and Ascorbic Acids by Nitric Acid”, DuPont SRP Inter Office Memorandum 780000302, June 23, 1978.

${ }^{v}$ Mirkin, I. A., and Koltunov, V. S., "Kinetics of the Oxidation of Oxalic Acid and Oxalates with Aqueous Nitric Acid”, Zhurnal Fizicheskoi Khimii, vol. 29, pp. 2163-2172 (1955).

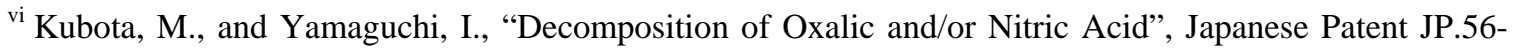
129079.A (1981).

vii Gray, L. W., Burney, G. A., and King, C. M., "Separation of Americium-241 from Calcium and Lead using Masking and Multiple Oxalate Precipitation Techniques”, DP-1765, August 1988.

viii Bibler, N. E., “Oxidation of H2C2O4 by HNO3-Mn in F-Canyon”, DPST-79-00278, March 1, 1979. 
${ }^{\text {ix }}$ Duke, F. R., "The Theory and Kinetics of Specific Oxidation. I. The Trivalent Manganese Oxalate Reaction”, Journal of the American Chemical Society, vol. 69, pp. 2885-2888, (1947).

${ }^{x}$ Kubota, M., "Decomposition of Oxalic Acid with Nitric Acid”, Journal of Radioanalytical Chemistry, Vol. 75, Nos. 1-2, pp. 39-49 (1982)

${ }^{x i}$ Freidlin, G. N., Golubko, L. A., Romanova, L. G., "Stability of Oxalic Acid in Nitrate Solutions", Zhurnal Prikladnoi Khimii, vol. 45, issue 9, pp. 2119-2121 (1972).

xii Germain, M., and Pasquiou, J. "Process for the Treatment of Nitric Acid Aqueous Effluents Containing Oxalic Acid, Usable in Particular for Treating the Mother Liquors from the Precipitation of Plutonium Oxalate.” French patent FR2554434, Commissariat A L'Energie Atomique May 1985.

xiii Kubota, M., and Miyashiro, H., "Method for Decomposing Oxalic Acid and/or Oxalic Acid Ion”, Japanese Patent JP.62-176593.A (1987).

xiv Vamplew, P. A., and Singer, K., "The Kinetics of Oxidation by Nitrous and Nitric Acid. III. Oxidation of Oxalic Acid by Nitrous Acid”, Journal of the Chemical Society, pp. 1143-1146 (1956).

${ }^{x v}$ Mailen, J. C., Tallent, O. K., and Arwood, P. C., "Destruction of Oxalate by Reaction with Hydrogen Peroxide”, ORNL/TM-7474, September 1981.

${ }^{\text {xvi }}$ Chung, D. Y., Kim, E. H., Shin, Y. J., Yoo, J. H., Choi, C. S., and Kim, J. D., "Decomposition of Oxalate by Hydrogen Peroxide in Aqueous Solution”, Journal of Radioanalytical and Nuclear Chemistry, Letters, vol. 201, number 6, (1995).

xvii Fenton, H. J. H., “Oxidation of Tartaric Acid in the Presence of Iron”, Journal of the Chemical Society (London), pp. 899-910, (1894).

xviii Kulik, N., Panova, Y., and Trapido, M., "The Fenton Chemistry and Its Combination with Coagulation for Treatment of Dye Solutions”, Separation Science and Technology, vol. 42, pp. 1521-1534 (2007).

xix Kelley, R. L., Gauger, W. K., and Srivastava, V. J., “Application of Fenton’s Reagent as a Pretreatment Step in Biological Degradation of Polyaromatic Hydrocarbons”, paper CONF-901212 presented at the Gas, Oil, Coal, and Environmental Biotechnology III Conference, New Orleans, LA, Dec. 1990.

${ }^{x x}$ Walton, J. H., and Graham, D. P., “A Study of the Oxidation of some Dicarboxylic Acids by Hydrogen Peroxide in the Presence of Certain Catalysts", Journal of the American Chemical Society, vol. 50, pp. 1641-1648 (1928).

${ }^{x x i}$ Hay, M. S., and Koopman, D. C., "Review of Alternative Enhanced Chemical Cleaning Options For SRS Waste Tanks”, SRNL-STI-2009-00500, August, 2009.

xxii Jeong, J., and Yoon, J., "pH Effect on $\mathrm{OH}$ Radical Production in Photo/ferrioxalate System", Water Research, vol. 39, no. 13, pp. 2893-2900, (2005).

xxiii Skoog, D. A., and West, D. M., “Analytical Chemistry”, second edition, Holt, Rhinehart, and Winston, 1974, pp. 354-358.

xxiv Dukkanci, M., and Gunduz, G., "Ultrasonic Degradation of Oxalic Acid in Aqueous Solutions", Ultrasonics Sonochemistry, vol. 13, pp. 517-522 (2006).

${ }^{\mathrm{xxv}}$ Shende, R. V., and Mahajani, V. V., "Kinetics of Wet Air Oxidation of Glyoxalic Acid and Oxalic Acid”, Industrial and Engineering Chemistry Research, vol. 33, 3125-3130 (1994). 
xxvi Smith, R. H., “HB-Line Pu-239 Production Flowsheet Strategy (U)”, SRNS-E1100-2011-00025, rev. 0, October 12, 2011.

${ }^{x x v i i}$ Facer, J. F., and Harmon, K. M.,”Precipitation of Plutonium(IV) Oxalate”, Hanford Atomic Products Operation, Richland, Washington, HW-31186, March 30, 1954, declassified with deletions December 7, 1962.

xxviii Hoyt, R. C., “Interim Report on Plutonium Oxalate Precipitation Work, 1/5/82 to 3/15/83”, Rockwell Hanford Supporting Document SD-CP-TI-014, June 8, 1983.

${ }^{x x i x}$ Reas, W. H., "Identification of Plutonium(IV) Oxalate Complexes in Oxalic Acid Solutions", Paper 4.9 in "The Transuranium Elements", G. T. Seaborg, J. J. Katz, and W. M. Manning, editors, McGraw Hill Book Company, 1949.

${ }^{x x x}$ Mandleburg, C. J., Francis, K. E., and Smith, R., "The Solubility of Plutonium Trifluoride, Plutonium Tetrafluoride, and Plutonium(IV) Oxalate in Nitric Acid Mixtures", Journal of the Chemical Society, pp. 2464 (1961).

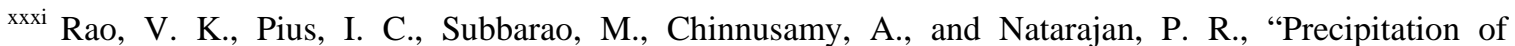
Plutonium Oxalate from Homogeneous Solutions", Journal of Radioanalytical and Nuclear Chemistry, Articles, vol. 100, number 1, pp. 129-134 (1986).

xxxii Gel'man, A. D., Moskvin, A. I., Zaitsev, L. M., and Mefod'eva, M. P., “Complex Compounds of Transuranium Elements”, translation from Russian, Consultants Bureau, NY (1962).

xxxiii Martel, A. E., and Smith, R. M., “Critical Stability Constants, Volume 3: Other Organic Ligands”, Plenum Press, NY (1977).

${ }^{\text {xxxiv }}$ Dean, J. A., editor, “Lange’s Handbook of Chemistry”, 15 $5^{\text {th }}$ edition, McGraw Hill, NY, 1999.

${ }^{x x x v}$ Krot, N. N., Ermolaev, N. P., and Gel'man, A. D., "The Behavior of Ethylenediaminetetraacetic Acid in Acid Solutions and its Reaction with Uranium (IV)”, Russian Journal of Inorganic Chemistry, vol. 7, no. 9, pp. 1062-1065, September 1962.

xxxvi Cleveland, J. M., “The Chemistry of Plutonium”, Gordon and Breach Science Publishers, NY, (1970)

${ }^{\text {xxxvii }}$ Fardy, J. J., and Pearson, J. M., "An Ion Exchange Study of the Sulphate Complexes of Plutonium(IV)”, Journal of Inorganic and Nuclear Chemistry, vol. 36, pp. 671-677, (1974).

xxxviii Sarver, L. A., and Brinton, P. H., "The Solubilities of some Rare-Earth Oxalates," Journal of the American Chemical Society, vol. 49, pp. 943-958 (1927).

${ }^{\text {xxxix }}$ CRC Handbook of Chemistry and Physics, 56 ${ }^{\text {th }}$ Edition, CRC Press, Cleveland OH (1975).

${ }^{\mathrm{xl}}$ International Critical Tables of Numerical Data, Physics, Chemistry, and Technology, Vol. III, E. W. Washburn, editor-in-chief, McGraw-Hill, New York, NY (1928). 


\section{Distribution:}
A. B. Barnes, 999-W
S. D. Fink, 773-A
B. J. Giddings, 786-5A
C. C. Herman, 999-W
S. L. Marra, 773-A
F. M. Pennebaker, 773-42A
W. R. Wilmarth, 773-A
E. A. Kyser, 773-A
R. A. Pierce, 773-A
T. S. Rudisill, 773-A
M. L. Crowder, 773-A
W. D. King, 773-42A
W. E. Daniel, 999-W
W. E. Harris, 704-2H
J. B. Schaade, 704-2H
G. J. Zachman, 225-7H
P.B. Andrews, 704-2H
S.J. Howell, 221-H
J.C. Wallace, 221-H
M. J. Swain, 703-H
W. G. Dyer, 704-2H
K.J. Gallahue, 221-H
S. L. Garrison, 704-2H
K. P. Burrows, 704-2H
J. W. Christopher, 704-2H
S. A. Thomas, 703-46A 